\title{
Lactobacillus plantarum and Lactobacillus helveticus modulate SIRT1, Caspase 3 and Bcl-2 in the testes of high-fructose-fed rats
}

\author{
Onur Gökhan Yıldırım¹ (D, Gökhan Sadi² (i), Fatma Akar ${ }^{3}$ (D) \\ 'Artvin Coruh University, Vocational School of Health Services, Department of Pharmacy Services, Artvin, Turkey \\ ${ }^{2}$ Karamanoglu Mehmetbey University, K. Ö. Science Faculty, Department of Biology, Karaman, Turkey \\ ${ }^{3}$ Gazi University, Faculty of Pharmacy, Department of Pharmacology, Ankara, Turkey
}

ORCID IDs of the authors: 0.G.Y. 0000-0003-0090-7369; G.S. 0000-0002-6422-1203; F.A. 0000-0002-5432-0304

Cite this article as:Yildirim, O. G., Sadi, G., \& Akar, F. (2020). Lactobacillus plantarum and Lactobacillus helveticus modulate SIRT1, Caspase 3 and Bcl-2 in the testes of high-fructose-fed rats. Istanbul Journal of Pharmacy, 50 (3), 168-175.

\begin{abstract}
Background and Aims: The influence of a high-fructose diet and probiotics on the male reproductive system and the testicular apoptotic pathway has been poorly documented. In this study, we aimed to investigate the influence of Lactobacillus plantarum and Lactobacillus helveticus supplementation on apoptotic factors such as sirtuin1, caspase 3 and bcl-2 on the testicular tissue of high-fructose-fed rats.

Methods: Fructose was given to the rats as a $20 \%$ solution in drinking water for 15 weeks. Gene expressions were established by real-time PCR. Protein levels were determined by Western blot analysis.

Results: Fructose consumption did not change mRNA expression of SIRT1, but did resulted in a decreased protein level. Dietary fructose reduced bcl-2 mRNA and protein expressions, whereas no changes were observed in the gene and protein expression levels of factor caspase-3. Both Lactobacillus supplementations increased SIRT1 protein expression without changing the mRNA levels in fructose-fed rats. The supplementations with both probiotics produced a significant downregulation on caspase 3 mRNA and protein levels. Bcl-2 proetin level increases with both probiotics supplementation while, mRNA level did not show difference in L. plantarum, but increased in L. helveticus supplementation.

Conclusion: Treatments with L.plantarum and L.helveticus can reduce testicular apoptosis induced by dietary high-fructose in rats via suppressing caspase 3 and promoting sirt 1 and bcl-2 protein expressions.
\end{abstract}

Keywords: Dietary fructose, Lactobacillus plantarum, Lactobacillus helveticus, apoptosis, testes

\section{INTRODUCTION}

Metabolic syndrome (MetS), which can be promoted by excessive fructose consumption, is the main health problem that affects people life quality along with the worldwide due to its many complications such as glucose intolerance, central adiposity, hyperlipidemia, hypertension, fatty liver disease and chronic low-grade inflammation (Dandona \& Dhindsa, 2011; Morrison \& Brannigan, 2015; Rastrelli, Filippi, Sforza, Maggi, \& Corona, 2018; Tsai, Matsumoto, Fujimoto, \& Boyko, 2004). In recent studies, it has been shown that low testosterone levels, one of the several factors responsible for male infertility, is commonly associated with metabolic syndrome, obesity, and Type-2 diabetes (Caldas, Porto, Motta, \& Casulari, 2009; Dhindsa et al., 2010; Ebrahimi et al., 2017). Studies have shown that low testosterone levels may enhance oxidative stress and also trigger apoptosis of Germ cells and Sertoli cells (Chaki et al., 2006; Simoes et al., 2013). However, the roles of apoptosis in fructose-related MetS and testicular homeostasis has not been investigated. In recent years, studies in rodents showed that diabetes causes increased inflammation and testicular oxidative stress as well as elevat- 
ed Bax/Bcl2 ratio and caspase-dependent apoptosis (Nna, Bakar, Ahmad, \& Mohamed, 2018; L. Zhao et al., 2017). The consumption of $10 \%$ fructose in drinking water for 8 weeks significantly increased apoptosis-associated speck-like protein (ASC) and caspase-1 levels of rat kidneys (Hu, Zhang, Pan, Li, \& Kong, 2012). A recent study demonstrated that a high consumption of fructose (35\% of daily calories) increased $\mathrm{Bax} / \mathrm{Bcl} 2$ ratio and the number of apoptotic cells compared to the control in the liver of mice (Choi, Abdelmegeed, \& Song, 2017). It has been reported that rats fed with a fructose diet have the activation of pro-apoptotic c-Jun N-terminal kinase (JNK) and apoptotic caspase3 in the liver and pancreatic tissues (Balakumar et al., 2016). We have previously shown that a high-fructose diet causes down-regulation of SIRT1 and up-regulation of iNOS protein expressions in the aorta of rats (Akar et al., 2012; Babacanoglu, Yildirim, Sadi, Pektas, \& Akar, 2013). In rats administered with 30\% fructose in drinking water, an induction of apoptosis was found and an increase in $\mathrm{Bax} / \mathrm{BCl} 2$ ratio and caspase-3 levels in the aorta were detected (Lu, Zhao, Yao, \& Zhang, 2017). The consumption of 10\% fructose in drinking water initiated apoptosis with increased Tumor necrosis factor-a (TNF-a) and p53 levels, while it suppressed SIRT1 of rat liver (L. Song et al., 2019). In another study, the administration of $30 \%$ fructose in drinking water caused structural abnormalities and increased apoptotic cell number in the testes of rats (Meydanli et al., 2018). In our previous study, dietary highfructose enhanced mitogenic protein IGF-1R and inflammatory markers such as iNOS, IL-1 $\beta$, and TNF-a expressions which are accompanied by low testosterone in the testes of rats. Besides, our histological examination demonstrated intratubular degeneration in the testes of fructose-fed rats (Yildirim et al., 2019).

Probiotics are living microorganisms that benefit their host and are used to prepare fermented products (Hotel \& Cordoba, 2001; Rosa et al., 2016). The beneficial effects of probiotics on health are accepted worldwide. Probiotics may be useful in reducing cardiovascular risk factors from pathological conditions such as type 2 diabetes (Hendijani \& Akbari, 2018; Markowiak \& Slizewska, 2017). Increased adipocyte inflammation, liver fat accumulation, and apoptosis due to high-fat and fructose diets were significantly suppressed by Lactobacillus (L.) rhamnosus supplementation (Q. Liu et al., 2020). Another study reported that high-fructoseinduced increases in plasma glucose, insulin and triglyceride levels, oxidative stress, and hepatic lipogenesis were reduced with L. curvatus and L. plantarum supplementations (Park, Ahn, Huh, McGregor, \& Choi, 2013). In our recent study, an L. plantarum and L. helveticus supplementation in high-fructose-fed rats reduced plasma insulin levels and improved kidney antioxidant parameters (Korkmaz et al., 2019a). Also, the consumption of these probiotics improved the insulin signaling pathway in the kidney and liver of rats fed with fructose (Korkmaz et al., 2019b; Sumlu, Bostanci, Sadi, Alcigir, \& Akar, 2020). In this study, we aimed to find the effectiveness of $L$. plantarum and $L$. helveticus on the apoptotic targets in the testes of high-fructose-fed rats.

\section{MATERIALS AND METHODS}

\section{Animal and diets}

The Ethical Animal Research Committee of Afyon Kocatepe University (Akuhadyek-49533702), in compliance with the
Guide for the Care and Use of Laboratory Animals (National Research Council Committee 2011) approved the protocol for animal use. Three-week-old male Wistar rats were housed in temperature- and humidity-controlled rooms $\left(20-22^{\circ} \mathrm{C}\right.$, 40$50 \%$ relative humidity) with a 12 -h light-dark cycle. The rats were fed with a standard rodent chow diet composed of $62 \%$ starch, $23 \%$ protein, $4 \%$ fat, $7 \%$ cellulose, standard vitamins, and salt mixture. After acclimation for 1 week, the rats were randomly divided into 4 groups: control, fructose Fruc, fructose + L. plantarum (Fruc + LP), and fructose + L. helveticus (Fruc + LH). Fructose (Danisco Sweeteners OY, Finland) was given to the rats as a $20 \%$ solution $(\mathrm{w} / \mathrm{v})$ in drinking water, which was freshly prepared every day, ad libitum for 15 weeks. L. helveticus and L. plantarum were given by gastric gavage once a day for the final six weeks in $2 \mathrm{ml}$ saline solution at appropriate dosing ( $1 \times 10^{9}$ CFU per $100 \mathrm{~g}$ of body weight of animal). The same volume of saline was given to the control and fructose groups by the gavage for the same period. At the end of the experiment, the animals were anesthetized with a mixture of ketaminexylazine (100 and $10 \mathrm{mg} / \mathrm{kg}$, respectively, i.p.). The testicular tissues were immediately dissected and blotted dry. Then they were frozen in liquid nitrogen and stored at $-85^{\circ} \mathrm{C}$ until the gene and protein expression studies.

\section{Preparation of Lactobacillus plantarum and Lactobacil- Ius helveticus}

Lactobacillus helveticus and L. plantarum were cultured in De Man, Rogosa and Sharpe broth (MRS; Oxoid; Unipath Ltd., Basingstoke, Hampshire, England) at $30^{\circ} \mathrm{C}$ in a rotary shaker at 150 rpm. Stock cultures were stored at $-80^{\circ} \mathrm{C}$ in MRS broth including 20\% (v/v) glycerol. Erlenmeyer flasks containing 20 $\mathrm{ml}$ of MRS were inoculated with $1.5 \mathrm{ml}$ of glycerol stock culture. The cultures were incubated at $35^{\circ} \mathrm{C} \pm 1^{\circ} \mathrm{C}$ on a rotary shaker at $150 \mathrm{rpm}$ and grown to an optical density of 1.0 at $600 \mathrm{~nm}$ (cell density corresponding to $\left.1 \times 10^{8} \mathrm{CFU} / \mathrm{ml}\right)$. The culture was divided into $10 \mathrm{ml}$ tubes $\left(1 \times 10^{\circ} \mathrm{CFU}\right)$, then cells were harvested at $5000 \mathrm{~g}$ for $5 \mathrm{~min}$ at $4{ }^{\circ} \mathrm{C}$. The cell pellets were washed by isotonic saline solution and lyophilized under a freeze dryer.

\section{Determination of gene expressions with quantitative real-time polymerase chain reaction (qRT-PCR)}

Total RNAs were isolated from the testicular tissues using RNeasy total RNA isolation kit (Qiagen, Venlo, The Netherlands) as described in the manufacturer's protocol. After isolation, the amount and the quality of the total RNA were determined by spectrophotometry at 260/280nm and agarose gel electrophoresis. Then, $1 \mu \mathrm{g}$ total RNA was reverse transcribed to cDNA with a commercial first-strand cDNA synthesis kit (Thermo Fisher Scientific, USA). Sirt1, caspase 3 and bcl-2 gene expression levels were determined by a real-time quantitative polymerase chain reaction (qRT-PCR, LightCycler480 II, Roche, Basel, Switzerland). mRNA expressions were determined by mixing $1 \mu \mathrm{l}$ cDNA, $5 \mu \mathrm{l}$ 2X SYBR Green Master Mix (Roche, Basel, Switzerland) and $2 \mu \mathrm{l}$ primer pairs each (Table 1) at $0.5 \mu \mathrm{M}$ final concentrations in a total volume of $10 \mu \mathrm{l}$. qRT-PCR was performed as follows: initial denaturation at $95^{\circ} \mathrm{C}$ for $10 \mathrm{~min}$, denaturation at $95^{\circ} \mathrm{C}$ for $10 \mathrm{~s}$, annealing at $58{ }^{\circ} \mathrm{C}$ for $15 \mathrm{~s}$ and extension at $72{ }^{\circ} \mathrm{C}$ for $15 \mathrm{~s}$ with 40 repeated thermal cycles measuring the green fluorescence at the end of each extension step. All samples were performed in 


\section{Table 1. Primer sequences of sirt1, caspase $3, \mathrm{bcl}-2$ and internal standard gapdh used for the mRNA} expression determination.

\begin{tabular}{|lll|}
\hline Gene & Forward Primer Sequence $\left(5^{\prime} \rightarrow 3^{\prime}\right)$ & Reverse Primer Sequence $\left(5^{\prime} \rightarrow \mathbf{3}^{\prime}\right)$ \\
\hline sirt1 & CGGTCTGTCAGCATCATCTTCC & CGCCTTATCCTCTAGTTCCTGTG \\
caspase & GAGCTTGGAACGCGAAGAAA & CTCTGAGGTTAGCTGCATCG \\
bcl-2 & TTCCTGCATCTCATGCCAAG & TACCAATAGCACTTCGCGTC \\
gapdh & TGATGACATCAAGAAGGTGGTGAAG & TCCTTGGAGGCCATGTGGGCCAT \\
\hline
\end{tabular}

triplicate and the specificity of the PCR products was confirmed using melt analysis. The relative expression of genes with respect to the internal control; glyceraldehyde 3-phosphate dehydrogenase (gapdh) was measured with the efficiency corrected advance relative quantification tool provided by the LightCycler ${ }^{\ominus}$ 480 SW 1.5 .1 software.

\section{Determination of protein expressions by Western blot}

Testicular tissues were homogenized in 4-fold volumes of homogenization medium (50 mM Tris, $150 \mathrm{mM}$ sodium chloride, $5 \mathrm{mM}$ ethylenediaminetetraacetic acid, 1\%(w/w) Triton X-100, $0.26 \%(\mathrm{w} / \mathrm{v})$ sodium deoxycholate, $50 \mathrm{mM}$ sodium fluoride, 0.1 $\mathrm{mM}$ sodium orthovanadate and $0.2 \mathrm{mM}$ phenylmethylsulfonyl fluoride, pH:7.4) with Tissue Ruptor ${ }^{\mathrm{TM}}$ (Qiagen, Venlo, Netherlands) homogenizer and then the homogenates were centrifuged at $1500 \mathrm{~g}$ for $10 \mathrm{~min}$ at $+4{ }^{\circ} \mathrm{C}$. Then, the supernatants were collected and protein levels were determined using the Lowry method (Lowry, Rosebrough, Farr, \& Randall, 1951).

All groups total proteins $(50-100 \mu \mathrm{g})$ were separated by the SDS-PAGE method using Mini Protean Tetra electrophoresis (Bio-Rad Laboratories, Hercules CA, USA). The separated proteins were transferred onto the polyvinylidene fluoride membrane with a semi-dry electroblotting apparatus (TransBlot Turbo, BioRad, Germany) after which the membranes were blocked with $5 \%$ bovine serum albumin for $1 \mathrm{~h}$. Primary antibodies were utilized for priming the respective SIRT1 (AntiSIRT1 Rabbit IgG, Scbt sc-15404 1/500), Caspase3 (Anti-Caspase-3 Rabbit lgG, Sigma C8487 1/1000) and Bcl-2 (Anti-BCl-2 Rabbit lgG, Scbt 1/ 1000) proteins overnight at $+4{ }^{\circ} \mathrm{C}$.

Membranes for normalization were labeled with an internal control Gapdh protein [Anti-Gapdh Rabbit IgG, Scbt sc-25778, 1/2000]. After the primary antibody incubation and washing step, Horse Radish Peroxidase (HRP) conjugated secondary antibody (Goat anti-rabbit lgG-HRP conjugate, Scbt sc-2030, 1/10000) was incubated for 1 hour. Then the blots were treated with Clarity ${ }^{\mathrm{TM}}$ Western ECL (Bio-Rad Laboratories, Hercules, USA) substrate solution for $5 \mathrm{~min}$. Images of the blots were ob-

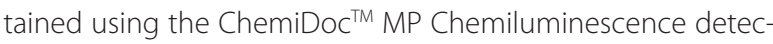
tion system (Bio-Rad Laboratories, USA) equipped with a CCD camera. The relative expression of the proteins with respect to Gapdh was calculated using the ImageLab 4.1 software.

\section{Statistical analysis}

The results are given as mean \pm standard error of the mean $(S E M) ; n$ is the number of rats. Statistical analyses were performed using the Student's t-test for unpaired data or one-way ANOVA followed by the Bonferroni post-hoc analysis. Values were evaluated with GraphPad Prism (version 6, GraphPad
Software, La Jolla, CA). Data were considered to be significantly different when the P-value was less than 0.05 .

\section{RESULTS}

Expression levels of genes related to testicular apoptosis sirt1, caspase 3 and bcl-2 were measured by qRT-PCR. As shown in Figure $1 \mathrm{a}$, neither dietary fructose nor the probiotic supplementations altered expression levels of SIRT1mRNA in the
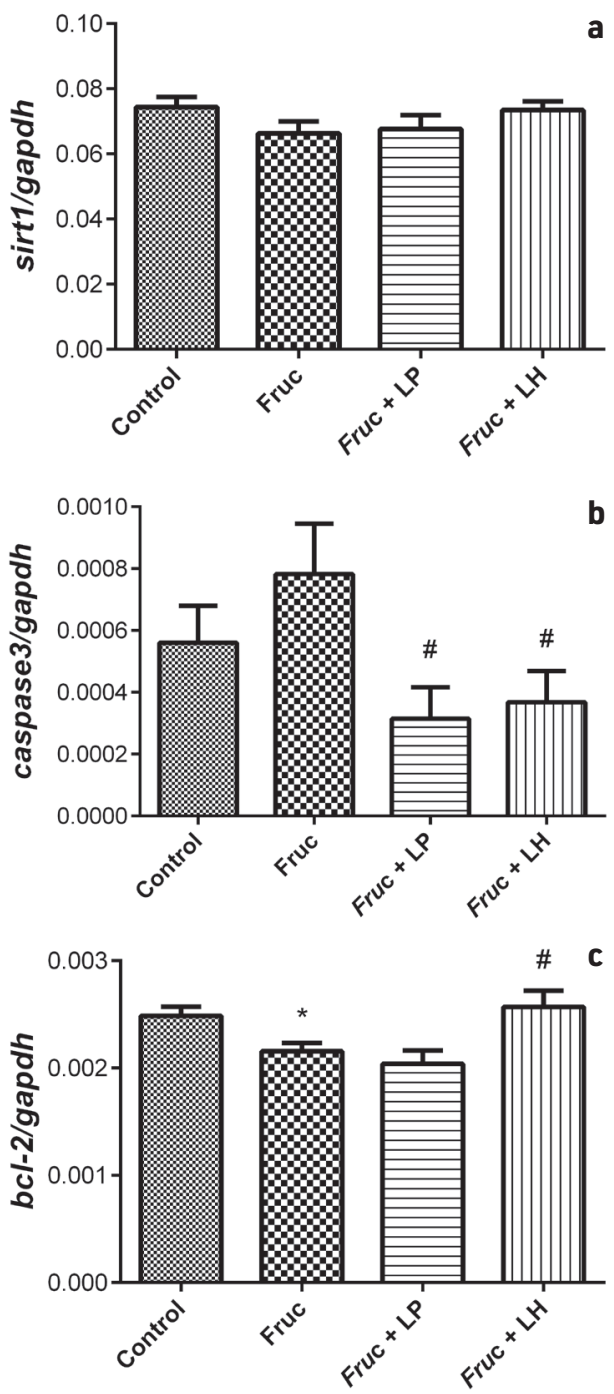

Figure 1. The mRNA expression levels of sirt1 (a), caspase3 (b) and bcl-2 (c) in the testes of Control, Fruc, Fruc + LP, and Fruc + LH groups. Data were normalized using gapdh. Values are expressed as mean \pm SEM, $n=6-8$. ${ }^{*} p<0.05$ versus control group; $\# p<.05$, significantly different from fructose group. Fruc: Fructose; LP: L. plantarum; LH: L. helveticus. 
Yıldırım et al. Lactobacillus plantarum and Lactobacillus helveticus modulate SIRT1, Caspase3 and Bcl-2 in the testes of high-fructose-fed rats

testicular samples of rats. There was a tendency toward an increase in the expression level of caspase 3 mRNA in the fructose-treated rats compared to the controls, but the differences did not achieve a significance level. However, L. plantarum and $L$. helveticus supplementations decreased the expression of caspase 3 mRNA in fructose-treated rats (Figure $1 \mathrm{~b}$ ). Importantly, the anti-apoptotic bcl-2 mRNA level was markedly decreased in fructose-fed rats, which was improved only with $L$. helveticus supplementation (Figure 1c).

The protein expression levels of SIRT1, caspase 3 and bcl-2 in testes samples of rats were determined by Western Blot analysis. Dietary fructose did not change the level of caspase3. However, L. helveticus and L. plantarum supplementations decreased this protein in the testicular tissue of high-fructose-fed rats. The expressions of SIRT1 and bcl-2 proteins were signifi- cantly decreased with a high-fructose diet, however, L. helveticus and L. plantarum supplementations markedly upregulated these proteins (Figure 2).

\section{DISCUSSION}

A high-fructose diet may cause glucose intolerance, hypertension, hyperlipidemia, and chronic low-grade inflammation. The development of metabolic disorders might be worsened by the activation of proinflammatory cytokine and oxidative stress. We have previously shown that high-fructose consumption enhances the expression of inflammatory factors in the testis, blood vessels, liver or adipose tissue accompanied by low testosterone level in the rats (Akar et al., 2012; Babacanoglu et al., 2013; Pektas, Koca, Sadi, \& Akar, 2016; Pektas, Sadi, \& Akar, 2015; Pektas et al., 2017; Sadi et al., 2015; Yildirim et al., a

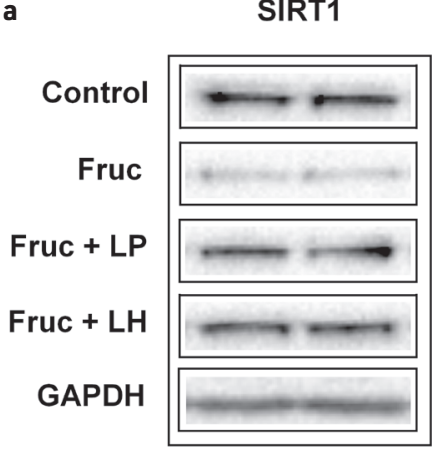

b

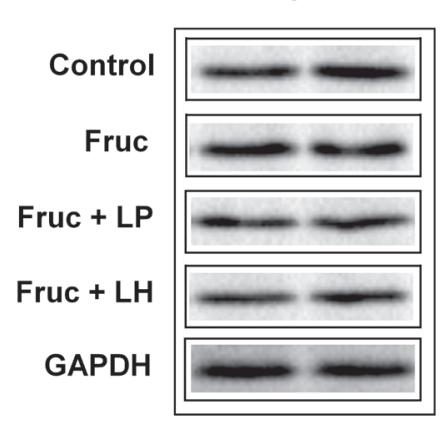

C

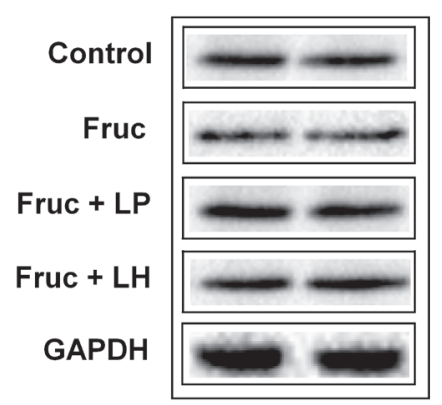

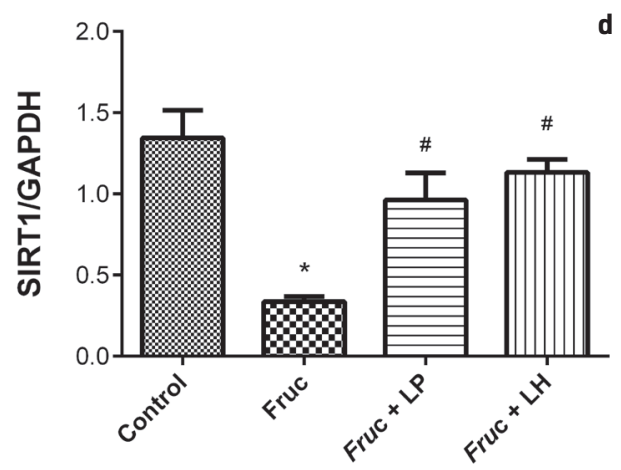
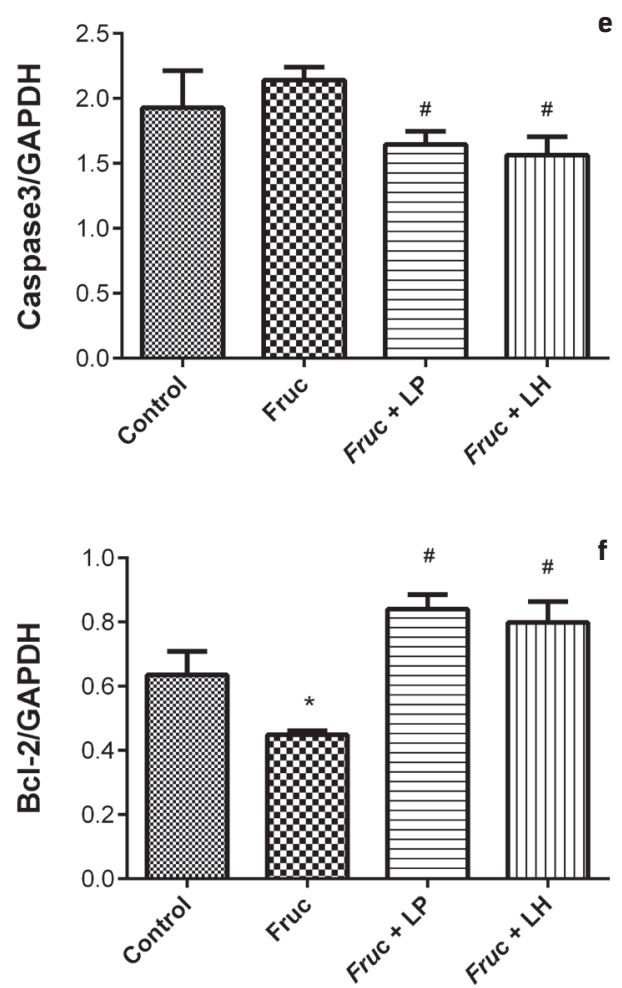

Figure 2. Representative Western blot bands (a-c) and relative protein expressions of SIRT1 (d), Caspase3 (e) and Bcl-2 (f) in the testes of Control, Fruc, Fruc + LP, and Fruc + LH groups. Data were normalized using Gapdh. Values are expressed as mean $\pm S E M, n=6-8$. ${ }^{*} p<0.05$ versus control group; \#p<.05, significantly different from fructose group: Fructose; LP: L. plantarum; LH: L. helveticus. 
2019). Diseases such as MetS, type 2 diabetes, and obesity are associated with hypogonadism in men (Caldas et al., 2009; Dhindsa et al., 2010; Ebrahimi et al., 2017).

Apoptotic pathways are evolutionarily maintained and play a pivotal role in homeostasis in the testicular tissue. Although regular apoptosis of spermatogenic cells is necessary to maintain testicular homeostasis, excessive cell death can cause infertility due to damaged spermatogenesis (Passos et al., 2007). When cells are exposed to irreparable oxidative stress, the cells force proapoptotic signals to eliminate the damaging materials (Green \& Llambi, 2015). Caspases and bcl-2 play important roles in cellular apoptotic processes. Previous studies showed that cell apoptosis can be suppressed due to caspase-3 inhibition with specific protease inhibitors (Cregan, Dawson, \& Slack, 2004; Hayashi, Kojima, \& Ito, 2006). SIRT1, which is a member of the nicotinamide adenine dinucleotide (NAD)-dependent protein deactylase family is associated with the regulatory control of diverse cellular process including energy homeostasis, inflammation, cell survival, apoptosis and DNA repair (Vachharajani et al., 2016; X.-I. Wang et al., 2016). Recent studies show that SIRT1 deficiency cause reproductive disorder due to diminished spermatogenesis and germ cell functions (Coussens, Maresh, Yanagimachi, Maeda, \& Allsopp, 2008; McBurney et al., 2003). SIRT1 and bcl-2 have an inhibitory effect on cell apoptosis playing an important role in apoptosis. Bax belongs to the same protein family as the bcl-2 gene but has an opposite function, and their equilibrium determines the degree of cell apoptosis (Brady \& Gil-Gomez, 1998; Cory, Huang, \& Adams, 2003; H. Liu et al., 2018; W. Song et al., 2016).

Low testosterone levels in animals may cause oxidative stress and also trigger Germ and Sertoli cells (SCs) apoptosis by increasing Bax/Bcl-2 ratio and caspase 3 activities (Chaki et al., 2006; Simoes et al., 2013). Streptozotocin-induced diabetes increases pro-apoptotic proteins, whereas Bax and Bad decrease the levels of SIRT1, bcl-2 and bcl-XL, which are antiapoptotic proteins in the rat testis. Besides, the weight of reproductive organs (testis and epididymis) and level of serum testosterone were decreased in the same diabetic rats compared to the control group (Koh, 2007a, 2007b; Tsounapi et al., 2012; Xu et al., 2014; Y. Zhao et al., 2012). In animal models, diabetes increases the expression of p53 and initiates apoptosis by activating caspase3 in rat testes (Alsemeh, Samak, \& El-Fatah, 2020; Faid, AlHussaini, \& Kilarkaje, 2015; Koh, 2007a; Y. Zhao et al., 2011). Additionally, the studies showed that diabetes increases testicular caspase 3 mRNA expression and suppresses bcl-2 mRNA and protein levels (Du, Qiu, Wang, \& Wang, 2018; Nna et al., 2018). Recent studies demonstrated that fructose consumption in rodents initiates apoptosis in several organs such as the kidney, pancreas, aorta, liver, and testes (Balakumar et al., 2016; Choi et al., 2017; Hu et al., 2012; Lu et al., 2017; Meydanli et al., 2018). In the present study, dietary fructose did not change testicular caspase 3 mRNA and protein levels. However, this dietary intervention decreased anti-apoptotic bcl-2 mRNA expression and protein level. In addition, the testicular SIRT1 protein level, but not mRNA expression, was dramatically decreased in the fructose-fed group. In a study on mice, increased testicular oxidative and nitrosative stress were shown to induce apoptosis by stimulating the p53-mediated Bax/caspase3 pathway (Shahin, Singh, \& Chaturvedi, 2018). In a previous study, we also showed that dietary high-fructose increased expression of iNOS, TNF-a, and NFkb mRNAs and caused testicular degeneration (Yildirim et al., 2019). All these results revealed that high-fructose consumption could activate testicular oxidative stress, inflammation and apoptosis in the rodents.

Studies in human and experimental animals proposed a link between metabolic diseases and intestinal microbiota (Backhed, Ley, Sonnenburg, Peterson, \& Gordon, 2005; Ley et al., 2005). Supplementation with Lactobacillus (L.) species, which is one of the primary components of human intestinal microbiota, was shown to produce antioxidant, antihyperlipidemic, antidiabetic, antiapoptotic, and anti-inflammatory activities in the experimental studies (Choi et al., 2017; Honda, Moto, Uchida, He, \& Hashizume, 2012; Korkmaz et al., 2019a; Mohammadi et al., 2019; Plaza-Diaz, Ruiz-Ojeda, Vilchez-Padial, \& Gil, 2017; Sumlu et al., 2020; H. F. Wang et al., 2012; Y. Wang et al., 2017). Metabolic irregularities including hyperglycemia, hyperinsulinemia, and dyslipidemia due to high-fructose consumption in rats were found to improve with L. acidophilus and L. casei supplements (Yadav, Jain, \& Sinha, 2007). Moreover, supplementations with L. plantarum and L. helveticus improved the insulin signaling pathway in the kidney and liver of rats fed with a high-fructose diet (Korkmaz et al., 2019a ; 2019b; Sumlu et al., 2020). The experiments experiments with probiotics, L. helveticus and L. plantarum supplementations were able to suppress apoptosis by decreasing caspase 3 and improving bcl-2 levels in different organs of the animals (Bouhafs, Moudilou, Exbrayat, Lahouel, \& Idoui, 2015; Girard et al., 2009; Huang et al., 2019; Mohammadi et al., 2019). Recently, a study showed that high-fat diet-induced adiposity, glucose intolerance and dyslipidemia were ameliorated by L. plantarum supplementation by increasing the expression of SIRT1 and PPARa in the liver and adipose tissues (Kwon et al., 2020). In our previous studies using L. plantarum and $L$. helveticus supplementations we determined that oral administration of these probiotics ( $1 \times 10^{9}$ CFU per $100 \mathrm{~g}$ of body weight of animal doses) for 6 weeks improved the deleterious effects of dietary fructose in the kidney and the liver (Korkmaz et al., 2019a; 2019b ; Sumlu et al., 2020).Therefore, in the current study we applied these two probiotics at the same dose for the same period. In this investigation, supplementation with L. plantarum and L. helveticus produced a marked downregulation on caspase 3 mRNA and protein levels in testicular samples of high-fructose-fed rats. Also, the testicular protein level of SIRT1 was significantly increased by both prebiotic supplementations in fructose-fed rats. Moreover, the decline in testicular bcl-2 mRNA and protein levels due to high-fructose consumption was improved by L. helveticus supplementation. However, while L. plantarum supplementation increased bcl-2 protein level, it did not change mRNA expression, showing a posttranslational improving effect on the antiapoptotic factor.

In conclusion, our data indicated that treatment with L. plantarum and L. helveticus species can reduce testicular apoptosis induced by dietary high-fructose in rats by suppressing 
caspase 3 and promoting SIRT1 and bcl-2 protein expressions. In practice, formulations containing these probiotics could show beneficial effects in certain reproductive irregularities of males.

\section{Peer-review: Externally peer-reviewed.}

Ethics Committee Approval: The experiments reported here complied with the current laws and regulations of the Turkish Republic on the care and handling of experimental animals and the local ethics committee of experimental animals of Afyon Kocatepe University (Akuhadyek-49533702).

Informed Consent: Written consent was obtained from the participants.

Author Contributions: Conception/Design of Study- F.A.; Data ACquisition- O.G.Y., G.S.; Data Analysis/Interpretation- G.S., F.A.; Drafting Manuscript- O.G.Y., F.A.; Critical Revision of Manuscript- G.S., F.A.; Final Approval and Accountability- O.G.Y., F.A.; Technical or Material SupportO.G.Y., G.S.; Supervision- F.A.

Conflict of Interest: The authors have no conflict of interest to declare.

Financial Disclosure: This work was supported by the Gazi University Research Fund under Grant [BAP 02/2017-20].

\section{REFERENCES}

- $\quad$ Akar, F., Uludag, O., Aydin, A., Aytekin, Y. A., Elbeg, S., Tuzcu, M., \& Sahin, K. (2012). High-fructose corn syrup causes vascular dysfunction associated with metabolic disturbance in rats: protective effect of resveratrol. Food and Chemical Toxicology, 50(6), 2135-2141.

- $\quad$ Alsemeh, A. E., Samak, M. A., \& El-Fatah, S. S. A. (2020). Therapeutic prospects of hydroxytyrosol on experimentally induced diabetic testicular damage: potential interplay with AMPK expression. Cell and Tissue Research, 380(1), 173-189.

- Babacanoglu, C., Yildirim, N., Sadi, G., Pektas, M. B., \& Akar, F. (2013). Resveratrol prevents high-fructose corn syrup-induced vascular insulin resistance and dysfunction in rats. Food and Chemical Toxicology, 60, 160-167.

- Backhed, F., Ley, R. E., Sonnenburg, J. L., Peterson, D. A., \& Gordon, J. I. (2005). Host-bacterial mutualism in the human intestine. Science, 307(5717), 1915-1920.

- Balakumar, M., Raji, L., Prabhu, D., Sathishkumar, C., Prabu, P., Mohan, V., \& Balasubramanyam, M. (2016). High-fructose diet is as detrimental as high-fat diet in the induction of insulin resistance and diabetes mediated by hepatic/pancreatic endoplasmic reticulum (ER) stress. Molecular and Cellular Biochemistry, 423(1-2), 93-104.

- Bouhafs, L., Moudilou, E. N., Exbrayat, J. M., Lahouel, M., \& Idoui, T. (2015). Protective effects of probiotic Lactobacillus plantarum BJ0021 on liver and kidney oxidative stress and apoptosis induced by endosulfan in pregnant rats. Renal Failure, 37(8), 1370-1378.

- Brady, H. J. M., \& Gil-Gomez, G. (1998). Molecules in focus - Bax. The pro-apoptotic Bcl-2 family member, Bax. International Journal of Biochemistry and Cell Biology, 30(6), 647-650

- Caldas, A. D., Porto, A. L., Motta, L. D., \& Casulari, L. A. (2009). Relationship between insulin and hypogonadism in men with metabolic syndrome. Arquivos Brasileiros de Endocrinologia e Metabologia, 53(8), 1005-1011.

- Chaki, S. P., Misro, M. M., Gautam, D. K., Kaushik, M., Ghosh, D., \& Chainy, G. B. (2006). Estradiol treatment induces testicular oxidative stress and germ cell apoptosis in rats. Apoptosis, $11(8), 1427-$ 1437.
Choi, Y., Abdelmegeed, M. A., \& Song, B. J. (2017). Diet high in fructose promotes liver steatosis and hepatocyte apoptosis in C57BL/6J female mice: Role of disturbed lipid homeostasis and increased oxidative stress. Food and Chemical Toxicology, 103, 111-121.

Cory, S., Huang, D. C., \& Adams, J. M. (2003). The Bcl-2 family: roles in cell survival and oncogenesis. Oncogene, 22(53), 8590-8607.

- Coussens, M., Maresh, J. G., Yanagimachi, R., Maeda, G., \& Allsopp, R. (2008). Sirt1 deficiency attenuates spermatogenesis and germ cell function. PLoS One, 3(2), e1571.

- Cregan, S. P., Dawson, V. L., \& Slack, R. S. (2004). Role of AlF in caspase-dependent and caspase-independent cell death. Oncogene, 23(16), 2785-2796.

- Dandona, P., \& Dhindsa, S. (2011). Update: Hypogonadotropic hypogonadism in type 2 diabetes and obesity. Journal of Clinical Endocrinology and Metabolism, 96(9), 2643-2651.

- Dhindsa, S., Miller, M. G., McWhirter, C. L., Mager, D. E., Ghanim, H., Chaudhuri, A., \& Dandona, P. (2010). Testosterone concentrations in diabetic and nondiabetic obese men. Diabetes Care, 33(6), 1186-1192.

- $\quad$ Du, Z., Qiu, Z., Wang, Z., \&Wang, X. (2018). The inhibitory effects of soybean isoflavones on testicular cell apoptosis in mice with type 2 diabetes. Experimental and Therapeutic Medicine, 15(1), 305-309. Ebrahimi, F., Schuetz, P., Mueller, B., Urwyler, S. A., Donath, M. Y., \& Christ-Crain, M. (2017). Effects of IL-1 [beta] on the hypothalamic-pituitary-gonadal axis in men with obesity and metabolic syndrome-A randomized, double-blind, placebo-controlled trial. Paper presented at the 19th European Congress of Endocrinology. Endocrine Abstracts (2017) 49 EP687.

- $\quad$ Faid, I., Al-Hussaini, H., \& Kilarkaje, N. (2015). Resveratrol alleviates diabetes-induced testicular dysfunction by inhibiting oxidative stress and c-Jun N-terminal kinase signaling in rats. Toxicology and Applied Pharmacology, 289(3), 482-494.

- Girard, S. A., Bah, T. M., Kaloustian, S., Lada-Moldovan, L., Rondeau, I., Tompkins, T. A., ... Rousseau, G. (2009). Lactobacillus helveticus and Bifidobacterium longum taken in combination reduce the apoptosis propensity in the limbic system after myocardial infarction in a rat model. British Journal of Nutrition, 102(10), 1420-1425. Green, D. R., \& Llambi, F. (2015). Cell Death Signaling. Cold Spring Harbor Perspectives in Biology, 7(12), a006080.

Hayashi, K., Kojima, R., \& Ito, M. (2006). Strain differences in the diabetogenic activity of streptozotocin in mice. Biological and Pharmaceutical Bulletin, 29(6), 1110-1119.

- Hendijani, F., \& Akbari, V. (2018). Probiotic supplementation for management of cardiovascular risk factors in adults with type II diabetes: A systematic review and meta-analysis. Clinical Nutrition, 37(2), 532-541.

- Honda, K., Moto, M., Uchida, N., He, F., \& Hashizume, N. (2012). Antidiabetic effects of lactic acid bacteria in normal and type 2 diabetic mice. Journal of Clinical Biochemistry and Nutrition, 51(2), 96-101. Hotel, A. C. P., \& Cordoba, A. (2001). Health and nutritional properties of probiotics in food including powder milk with live lactic acid bacteria. Prevention, 5(1), 1-10.

Hu, Q. H., Zhang, X., Pan, Y., Li, Y. C., \& Kong, L. D. (2012). Allopurinol, quercetin and rutin ameliorate renal NLRP3 inflammasome activation and lipid accumulation in fructose-fed rats. Biochemical Pharmacology, 84(1), 113-125.

Huang, L., Zhao, Z., Duan, C., Wang, C., Zhao, Y., Yang, G., . . Li, S. (2019). Lactobacillus plantarum C88 protects against aflatoxin B 1-induced liver injury in mice via inhibition of NF-KB-mediated inflammatory responses and excessive apoptosis. BMC Microbiology, 19(1), 170.

Koh, P. O. (2007a). Streptozotocin-induced diabetes increases apoptosis through JNK phosphorylation and Bax activation in rat testes. Journal of Veterinary Medical Science, 69(9), 969-971. 
- Koh, P. O. (2007b). Streptozotocin-induced diabetes increases the interaction of $\mathrm{Bad} / \mathrm{BCl}-\mathrm{XL}$ and decreases the binding of $\mathrm{pBad} / 14$ 3-3 in rat testis. Life Sciences, 81(13), 1079-1084.

- Korkmaz, O. A., Sadi, G., Kocabas, A., Yildirim, O. G., Sumlu, E., Koca, H. B., ... Akar, F. (2019a). Lactobacillus helveticus and Lactobacillus plantarum modulate renal antioxidant status in a rat model of fructose-induced metabolic syndrome. Archives of Biological Sciences, 71(2), 265-273.

- Korkmaz, O. A., Sumlu, E., Koca, H. B., Pektas, M. B., Kocabas, A., Sadi, G., \& Akar, F. (2019b). Effects of Lactobacillus Plantarum and Lactobacillus Helveticus on Renal Insulin Signaling, Inflammatory Markers, and Glucose Transporters in High-Fructose-Fed Rats. Medicina (Kaunas, Lithuania), 55(5), 207.

- Kwon, J., Kim, B., Lee, C., Joung, H., Kim, B.-K., Choi, I. S., \& Hyun, C.K. (2020). Comprehensive amelioration of high-fat diet-induced metabolic dysfunctions through activation of the PGC-1a pathway by probiotics treatment in mice. PLoS One, 15(2), e0228932.

- Ley, R. E., Backhed, F., Turnbaugh, P., Lozupone, C. A., Knight, R. D., \& Gordon, J. I. (2005). Obesity alters gut microbial ecology. Proceedings of the National Academy of Sciences of the United States of America, 102(31), 11070-11075.

- $\quad$ Liu, H., Zhang, S., Liu, C., Wu, J., Wang, Y., Yuan, L., . . Zhuang, D. (2018). Resveratrol ameliorates microcystin-LR-induced testis germ cell apoptosis in rats via SIRT1 signaling pathway activation. Toxins, 10(6), 235.

- $\quad$ Liu, Q., Liu, Y., Li, F., Gu, Z., Liu, M., Shao, T., .. Feng, W. (2020). Probiotic culture supernatant improves metabolic function through FGF21-adiponectin pathway in mice. The Journal of Nutritional Biochemistry, 75, 108256.

- Lowry, O. H., Rosebrough, N. J., Farr, A. L., \& Randall, R. J. (1951). Protein measurement with the Folin phenol reagent. Journal of Biological Chemistry, 193(1), 265-275.

- Lu, X. L., Zhao, C. H., Yao, X. L., \& Zhang, H. (2017). Quercetin attenuates high fructose feeding-induced atherosclerosis by suppressing inflammation and apoptosis via ROS-regulated PI3KJAKT signaling pathway. Biomedicine and Pharmacotherapy, 85, 658-671.

- Markowiak, P., \& Slizewska, K. (2017). Effects of Probiotics, Prebiotics, and Synbiotics on Human Health. Nutrients, 9(9), 1021.

- McBurney, M. W., Yang, X., Jardine, K., Hixon, M., Boekelheide, K., Webb, J. R., ... Lemieux, M. (2003). The mammalian SIR2a protein has a role in embryogenesis and gametogenesis. Molecular and cellular biology, 23(1), 38-54.

- Meydanli, E. G., Gumusel, A., Ozkan, S., Tanriverdi, G., Balci, M. B. C., Develi Is, S., ... Bekpinar, S. (2018). Effects of resveratrol on highfructose-induced testis injury in rats. Ultrastructural Pathology, 42(1), 65-73.

- Mohammadi, G., Dargahi, L., Naserpour, T., Mirzanejad, Y., Alizadeh, S. A., Peymani, A., \& Nassiri-Asl, M. (2019). Probiotic mixture of Lactobacillus helveticus R0052 and Bifidobacterium longum R0175 attenuates hippocampal apoptosis induced by lipopolysaccharide in rats. International Microbiology, 22(3), 317-323.

- Morrison, C. D., \& Brannigan, R. E. (2015). Metabolic syndrome and infertility in men. Best Practice \& Research: Clinical Obstetrics \& Gynaecology, 29(4), 507-515.

- Nna, V. U., Bakar, A. B. A., Ahmad, A., \& Mohamed, M. (2018). Diabetes-induced testicular oxidative stress, inflammation, and caspase-dependent apoptosis: the protective role of metformin. Archives of Physiology and Biochemistry, 1-12.

- $\quad$ Park, D. Y., Ahn, Y. T., Huh, C. S., McGregor, R. A., \& Choi, M. S. (2013). Dual probiotic strains suppress high fructose-induced metabolic syndrome. World Journal of Gastroenterology, 19(2), 274-283.

- Passos, J. F., Saretzki, G., Ahmed, S., Nelson, G., Richter, T., Peters, H., ... von Zglinicki, T. (2007). Mitochondrial dysfunction accounts for the stochastic heterogeneity in telomere-dependent senescence. PLoS Biology, 5(5), e110.
Pektas, M. B., Koca, H. B., Sadi, G., \& Akar, F. (2016). Dietary Fructose Activates Insulin Signaling and Inflammation in Adipose Tissue: Modulatory Role of Resveratrol. BioMed Research International, 2016, 8014252 .

Pektas, M. B., Sadi, G., \& Akar, F. (2015). Long-Term Dietary Fructose Causes Gender-Different Metabolic and Vascular Dysfunction in Rats: Modulatory Effects of Resveratrol. Cellular Physiology and Biochemistry, 37(4), 1407-1420.

Pektas, M. B., Yucel, G., Koca, H. B., Sadi, G., Yildirim, O. G., Ozturk, G., \& Akar, F. (2017). Dietary Fructose-Induced Hepatic Injury in Male and Female Rats: Influence of Resveratrol. Drug Research (Stuttg), 67(2), 103-110.

Plaza-Diaz, J., Ruiz-Ojeda, F. J., Vilchez-Padial, L. M., \& Gil, A. (2017). Evidence of the Anti-Inflammatory Effects of Probiotics and Synbiotics in Intestinal Chronic Diseases. Nutrients, 9(6), 555.

- Rastrelli, G., Filippi, S., Sforza, A., Maggi, M., \& Corona, G. (2018). Metabolic syndrome in male hypogonadism. In Metabolic Syndrome Consequent to Endocrine Disorders (Vol. 49, pp. 131-155): Karger Publishers.

- Rosa, D. D., Grzeskowiak, L. M., Ferreira, C. L., Fonseca, A. C., Reis, S. A., Dias, M. M., ... Peluzio Mdo, C. (2016). Kefir reduces insulin resistance and inflammatory cytokine expression in an animal model of metabolic syndrome. Food \& Function, 7(8), 3390-3401.

- Sadi, G., Ergin, V., Yilmaz, G., Pektas, M. B., Yildirim, O. G., Menevse, A., \& Akar, F. (2015). High-fructose corn syrup-induced hepatic dysfunction in rats: improving effect of resveratrol. European Journal of Nutrition, 54(6), 895-904.

- $\quad$ Shahin, S., Singh, S. P., \& Chaturvedi, C. M. (2018). 2.45 GHz microwave radiation induced oxidative and nitrosative stress mediated testicular apoptosis: Involvement of a p53 dependent bax-caspase-3 mediated pathway. Environmental Toxicology, 33(9), 931-945. Simoes, V. L., Alves, M. G., Martins, A. D., Dias, T. R., Rato, L., Socorro, S., \& Oliveira, P. F. (2013). Regulation of apoptotic signaling pathways by 5 alpha-dihydrotestosterone and 17 beta-estradiol in immature rat Sertoli cells. Journal of Steroid Biochemistry and Molecular Biology, 135, 15-23.

- Song, L., Chen, T. Y., Zhao, X. J., Xu, Q., Jiao, R. Q., Li, J. M., \& Kong, L. D. (2019). Pterostilbene prevents hepatocyte epithelial-mesenchymal transition in fructose-induced liver fibrosis through suppressing miR-34a/Sirt1/p53 and TGF- $\beta 1 /$ Smads signalling. British journal of pharmacology, 176(11), 1619-1634.

- Song, W., Liu, M. G., Zhang, J. B., Zhang, J. J., Sun, M. M., \& Yu, Q. K. (2016). Mechanism of action of EBV, Bcl-2, p53, c-Myc and Rb in non-Hodgkin's lymphoma. European Review for Medical and Pharmacological Sciences, 20(6), 1093-1097.

Sumlu, E., Bostanci, A., Sadi, G., Alcigir, M. E., \& Akar, F. (2020). Lactobacillus plantarum improves lipogenesis and IRS-1/AKT/eNOS signalling pathway in the liver of high-fructose-fed rats. Archives of Physiology and Biochemistry, 1-9.

Tsai, E. C., Matsumoto, A. M., Fujimoto, W. Y., \& Boyko, E. J. (2004). Association of bioavailable, free, and total testosterone with insulin resistance: influence of sex hormone-binding globulin and body fat. Diabetes Care, 27(4), 861-868.

Tsounapi, P., Saito, M., Dimitriadis, F., Koukos, S., Shimizu, S., Satoh, K., ... Sofikitis, N. (2012). Antioxidant treatment with edaravone or taurine ameliorates diabetes-induced testicular dysfunction in the rat. Molecular and Cellular Biochemistry, 369(1-2), 195-204. Vachharajani, V. T., Liu, T., Wang, X., Hoth, J. J., Yoza, B. K., \& McCall, C. E. (2016). Sirtuins link inflammation and metabolism. Journal of Immunology Research, 8167273.

Wang, H. F., Tseng, C. Y., Chang, M. H., Lin, J. A., Tsai, F. J., Tsai, C. H., ... Tsai, C. C. (2012). Anti-inflammatory effects of probiotic Lactobacillus paracasi on ventricles of BALB/C mice treated with ovalbumin. Chinese Journal of Physiology, 55(1), 37-46. 
- Wang, X.-l., Wu, L.-y., Zhao, L., Sun, L.-n., Liu, H.-y., Liu, G., \& Guan, G.-j. (2016). SIRT1 activator ameliorates the renal tubular injury induced by hyperglycemia in vivo and in vitro via inhibiting apoptosis. Biomedicine \& Pharmacotherapy, 83, 41-50.

- Wang, Y., Wu, Y., Wang, Y., Xu, H., Mei, X., Yu, D., .. Li, W. (2017). Antioxidant Properties of Probiotic Bacteria. Nutrients, 9(5), 521.

- $\quad$ Xu, Y., Lei, H., Guan, R., Gao, Z., Li, H., Wang, L., ... Xin, Z. (2014). Studies on the mechanism of testicular dysfunction in the early stage of a streptozotocin induced diabetic rat model. Biochemical and Biophysical Research Communications, 450(1), 87-92.

- Yadav, H., Jain, S., \& Sinha, P. R. (2007). Antidiabetic effect of probiotic dahi containing Lactobacillus acidophilus and Lactobacillus casei in high fructose fed rats. Nutrition, 23(1), 62-68.

- Yildirim, O. G., Sumlu, E., Aslan, E., Koca, H. B., Pektas, M. B., Sadi, G., \& Akar, F. (2019). High-fructose in drinking water initiates activation of inflammatory cytokines and testicular degeneration in rat. Toxicology Mechanisms and Methods, 29(3), 224-232.
Zhao, L., Gu, Q., Xiang, L., Dong, X., Li, H., Ni, J., ... Chen, G. (2017). Curcumin inhibits apoptosis by modulating $\mathrm{Bax} / \mathrm{BCl}-2$ expression and alleviates oxidative stress in testes of streptozotocin-induced diabetic rats. Therapeutics and Clinical Risk Management, 13, 10991105.

- Zhao, Y., Tan, Y., Dai, J., Li, B., Guo, L., Cui, J., ... Cai, L. (2011). Exacerbation of diabetes-induced testicular apoptosis by zinc deficiency is most likely associated with oxidative stress, p38 MAPK activation, and p53 activation in mice. Toxicology Letters, 200(1-2), 100-106.

Zhao, Y., Tan, Y., Dai, J., Wang, B., Li, B., Guo, L., ... Cai, L. (2012). Zinc deficiency exacerbates diabetic down-regulation of Akt expression and function in the testis: essential roles of PTEN, PTP1B and TRB3. Journal of Nutritional Biochemistry, 23(8), 1018-1026. 